\title{
Article \\ Congenital Deletion of Nedd4-2 in Lung Epithelial Cells Causes Progressive Alveolitis and Pulmonary Fibrosis in Neonatal Mice
}

\author{
Dominik H. W. Leitz ${ }^{1,2,3,+}+^{\mathbb{D}}$, Julia Duerr ${ }^{1,2,3, *,+}{ }^{\mathbb{D}}$, Surafel Mulugeta $4{ }^{(\mathbb{D})}$, Ayça Seyhan Agircan ${ }^{2,3}$, \\ Stefan Zimmermann ${ }^{5}$, Hiroshi Kawabe ${ }^{6,7,8,9}$, Alexander H. Dalpke ${ }^{10}$ (D) Michael F. Beers ${ }^{4}$ \\ and Marcus A. Mall 1,2,3,11 (D)
}

check for

updates

Citation: Leitz, D.H.W.; Duerr, J.; Mulugeta, S.; Seyhan Agircan, A.; Zimmermann, S.; Kawabe, H.;

Dalpke, A.H.; Beers, M.F.; Mall, M.A. Congenital Deletion of Nedd4-2 in

Lung Epithelial Cells Causes

Progressive Alveolitis and Pulmonary Fibrosis in Neonatal Mice. Int. J. Mol. Sci. 2021, 22, 6146. https://doi.org/ $10.3390 /$ ijms 22116146

Academic Editor:

Alessandro Marchioni

Received: 7 May 2021

Accepted: 31 May 2021

Published: 7 June 2021

Publisher's Note: MDPI stays neutral with regard to jurisdictional claims in published maps and institutional affiliations.

Copyright: (c) 2021 by the authors. Licensee MDPI, Basel, Switzerland. This article is an open access article distributed under the terms and conditions of the Creative Commons Attribution (CC BY) license (https:/ / creativecommons.org/licenses/by/ $4.0 /)$.
1 Department of Pediatric Respiratory Medicine, Immunology and Critical Care Medicine, Charité-Universitätsmedizin Berlin, Corporate Member of Freie Universität Berlin and Humboldt-Universität zu Berlin, Augustenburger Platz 1, 13353 Berlin, Germany; dominik.leitz@charite.de (D.H.W.L.); marcus.mall@charite.de (M.A.M.)

2 Translational Lung Research Center (TLRC), Member of the German Center for Lung Research (DZL), Department of Translational Pulmonology, University of Heidelberg, Im Neuenheimer Feld 156, 69120 Heidelberg, Germany; aycaseyhanagircan@med.uni-heidelberg.de

3 German Center for Lung Research (DZL), Associated Partner Site, Augustenburger Platz 1, 13353 Berlin, Germany

4 Division of Pulmonary, Allergy, and Critical Care Medicine, Perelman School of Medicine, University of Pennsylvania, 3450 Hamilton Walk Suite 216, Philadelphia, PA 19104, USA; mulugeta@pennmedicine.upenn.edu (S.M.); mfbeers@pennmedicine.upenn.edu (M.F.B.)

5 Department of Infectious Diseases, Medical Microbiology and Hygiene, University of Heidelberg, 69120 Heidelberg, Germany; stefan.zimmermann@med.uni-heidelberg.de

6 Department of Molecular Neurobiology, Max Planck Institute of Experimental Medicine, Hermann-Rein-Str. 3D, 37075 Goettingen, Germany; kawabe@em.mpg.de

7 Laboratory of Molecular Life Science, Department of Gerontology, Institute of Biomedical Research and Innovation, Foundation for Biomedical Research and Innovation at Kobe, 2-2 Minatojima-Minamimachi Chuo-ku, Kobe 650-0047, Japan

8 Division of Pathogenetic Signaling, Department of Biochemistry and Molecular Biology, Kobe University Graduate School of Medicine, 1-5-6 Minatojima-minamimachi, Chuo-ku, Kobe 650-0047, Japan

9 Department of Pharmacology, Gunma University Graduate School of Medicine, 3-39-22 Showa-machi, Maebashi, Gunma 371-8511, Japan

10 Institute of Medical Microbiology and Virology, Medical Faculty, University Hospital Carl Gustav Carus Dresden, Technische Universität Dresden, 01307 Dresden, Germany; alexander.dalpke@ukdd.de

11 Berlin Institute of Health, Charité-Universitätsmedizin Berlin, Charitéplatz 1, 10117 Berlin, Germany

* Correspondence: julia.duerr@charite.de

$+\quad$ These authors contributed equally.

Abstract: Recent studies found that expression of NEDD4-2 is reduced in lung tissue from patients with idiopathic pulmonary fibrosis (IPF) and that the conditional deletion of Nedd4-2 in lung epithelial cells causes IPF-like disease in adult mice via multiple defects, including dysregulation of the epithelial $\mathrm{Na}^{+}$channel (ENaC), TGF $\beta$ signaling and the biosynthesis of surfactant protein-C proprotein (proSP-C). However, knowledge of the impact of congenital deletion of Nedd4-2 on the lung phenotype remains limited. In this study, we therefore determined the effects of congenital deletion of Nedd4-2 in the lung epithelial cells of neonatal doxycycline-induced triple transgenic Nedd4-2 flfl $/ C C S P-r t T A 2^{S}-M 2 / L C 1$ mice, with a focus on clinical phenotype, survival, lung morphology, inflammation markers in BAL, mucin expression, ENaC function and proSP-C trafficking. We found that the congenital deletion of Nedd4-2 caused a rapidly progressive lung disease in neonatal mice that shares key features with interstitial lung diseases in children (chILD), including hypoxemia, growth failure, sterile pneumonitis, fibrotic lung remodeling and high mortality. The congenital deletion of Nedd4-2 in lung epithelial cells caused increased expression of $M u c 5 b$ and mucus plugging of distal airways, increased ENaC activity and proSP-C mistrafficking. This model of congenital deletion of Nedd4-2 may support studies of the pathogenesis and preclinical development of therapies for chILD. 
Keywords: Nedd4-2; animal model; interstitial lung disease; chILD; ENaC; proSP-C

\section{Introduction}

Nedd4-2 is an E3 ubiquitin-protein ligase that participates in the posttranscriptional regulation of several proteins including $\mathrm{ENaC}, \mathrm{Smad} 2 / 3$ and proSP-C, which play key roles in multiple cellular processes such as epithelial ion and fluid transport, TGF $\beta$ signaling and surfactant biogenesis that are essential for epithelial homeostasis and lung health [1-8]. In a previous study, we found that NEDD4-2 is reduced in the lung tissue of patients with idiopathic pulmonary fibrosis (IPF) [9]. Further, we demonstrated that the conditional deletion of Nedd4-2 in lung epithelial cells by doxycycline induction of adult Nedd4-2 flffl/CCSP-rtTA2 $2^{S}-M 2 / L C 1$ mice, hereafter referred to as conditional Nedd4- $2^{-/-}$mice, causes a chronic progressive, restrictive lung disease that shares key features with IPF in patients including signature lesions such as radiological and histological honeycombing and fibroblast foci [9]. These studies also identified the dysregulation of (i) $\mathrm{ENaC}$, leading to airway surface liquid depletion and reduced mucociliary clearance; (ii) proSP-C biogenesis and (iii) TGF $\beta$ /Smad signaling, promoting fibrotic remodeling as epithelial defects and potential mechanisms triggering IPF-like disease in adult conditional Nedd4-2 ${ }^{-/}$mice [9].

Compared to the detailed characterization of the functional consequences and resulting pulmonary phenotype produced by the conditional deletion of Nedd4-2 in the lung epithelial cells of adult mice [9], current knowledge on the impact of the congenital deletion of Nedd4-2 on the lung phenotype in neonatal mice remains limited. A mouse line with constitutive systemic deletion of Nedd4-2 demonstrated that the majority of mice lacking Nedd4-2 died during or shortly after birth and that survivors developed substantial neutrophilic inflammation in the lungs at the age of 3 weeks [10]. Subsequent studies in mice with constitutive lung-specific deletion of Nedd4-2 using a "leaky" Nedd4-2flffl /Sftpc$r t T A / C r e$ triple transgenic system under the control of the surfactant protein C (Sftpc) promoter showed massive neutrophilic inflammation, aspects of cystic fibrosis-like lung disease and premature death 3-4 weeks after birth [11]. However, the lung phenotype of neonatal Nedd4-2 $2^{f l f l} / C C S P-r t T A 2^{S}-M 2 / L C-1$ mice, facilitating "tight" deletion of Nedd4-2 in alveolar type 2 (AT2) cells as well as club cells of the conducting airways under control of the club cells $10 \mathrm{kDa}$ secretory protein (CCSP) [12] promoter, has not been studied.

The aim of the present study was therefore to determine the effects of congenital deletion of Nedd4-2 in lung epithelial cells of neonatal Nedd4- $2^{f l f l} / C C S P-r t T A 2^{S}-M 2 / L C-1$ mice, hereafter referred to as congenital Nedd4-2-/- mice. Using physiologic, histopathologic, inflammatory and microbiological endpoints, we focused on the clinical phenotype including survival, lung morphology, inflammation markers in BAL, mucin $(M u c 5 b$ and $M u c 5 a c)$ expression in whole lung and airway mucus content, ENaC-mediated $\mathrm{Na}^{+}$transport in freshly excised tissues of the conducting airways and proSP-C trafficking in AT2 cells to provide a comprehensive characterization of the lung phenotype of congenital Nedd4-2 ${ }^{-/-}$mice, and to elucidate the impact of epithelial defects identified in adult conditional Nedd4- $2^{-/-}$mice in the neonatal lung. The results of this study validate a new mouse model that shares key aspects of interstitial lung diseases in children (chILD), and thus offers new opportunities for studies of the pathogenesis and therapy of these childhood lung diseases with high unmet need [13].

\section{Results}

2.1. Congenital Deletion of Nedd4-2 in Lung Epithelial Cells Causes Severe Hypoxemia, Failure to Thrive and Early Mortality in Neonatal Mice

To determine the effect of the congenital deletion of Nedd4-2 in epithelial cells of the neonatal mouse lung, we crossed mice carrying Nedd4-2 flanked by loxP sites (Nedd4-2 fl/fl $)$ with CCSP-rtTA2 ${ }^{S}-M 2^{S} / L C 1$ mice to enable tight doxycycline-dependent Cre expression for the targeted deletion of Nedd4-2 in club cells of the conducting airways and AT2 cells 
of the lung [9,12]. Dams were continuously fed with doxycycline from the first day of mating to obtain triple transgenic congenital Nedd4-2-/- mice. At 10 days after birth, before the onset of clinical signs of lung disease, body weight did not differ between congenital Nedd $42^{-/-}$mice $(5.4 \pm 0.08 \mathrm{~g})$ vs. littermate controls $(5.3 \pm 0.11 \mathrm{~g})$. Around 3 weeks after birth, congenital Nedd4-2 $2^{-1-}$ mice showed clinical symptoms of respiratory distress with severe hypoxemia (Figure 1a), weight loss (Figure 1b) and $~ 95 \%$ mortality within 4 weeks after birth (Figure 1c).

a

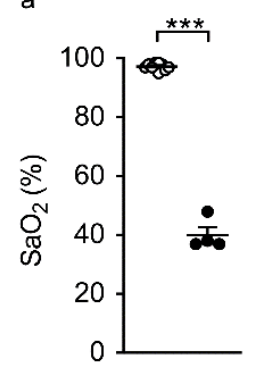

b

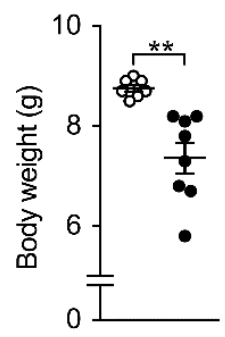

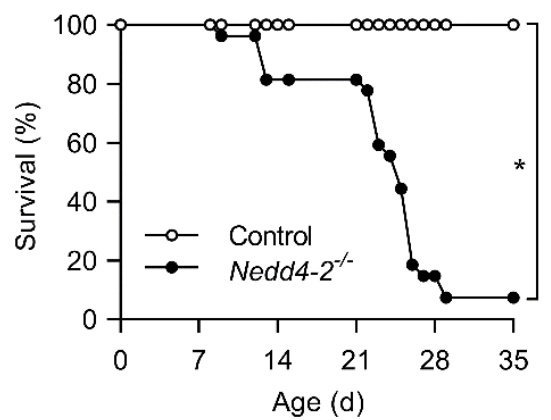

Figure 1. Congenital deletion of Nedd4-2 in lung epithelial cells causes severe hypoxemia, failure to thrive and high mortality in neonatal mice: $(\mathbf{a}, \mathbf{b})$ Oxygen saturation $(\mathbf{a})$ and body weight $(\mathbf{b})$ measured in 3-week-old mice. $n=4-13$ mice per group. ${ }^{* *} p<0.01,{ }^{* * *} p<0.001$. (c) Survival curve of congenital Nedd4-2 $2^{-/}$and control mice. $n=18-27$ mice per group. ${ }^{*} p<0.05$. Data are shown as mean \pm S.E.M.

\subsection{Congenital Deletion of Nedd4-2 in Lung Epithelial Cells Causes Alveolar Inflammation and} Fibrosis in Neonatal Mice

Microscopically, hematoxylin- and eosin (H\&E) stained lung sections from 10-dayold congenital Nedd4-2-/- mice did not show abnormalities compared to littermate controls (Figure 2a), whereas lung sections from 3-week-old congenital Nedd4-2-/- mice displayed patchy inflammatory infiltrates, especially in the periphery of the lung (Figure 2b). These same regions also showed evidence of epithelial hyperplasia and alveolitis, with large foamy macrophages and granulocytes infiltrating the alveolar airspaces in the affected areas (Figure 2b). Masson-Goldner-Trichrome staining of lung sections of 3-week-old congenital Nedd4-2 $2^{-/-}$mice showed substantial collagen deposition in affected lung regions (Figure 2c). The use of multiple control lines established that the observed phenotype was not caused by off-target effects of rtTA, Cre recombinase or doxycycline and that the expression system was tight in the absence of doxycycline (Figure A1, Appendix A).

\subsection{Development of Pneumonitis in Congenital Nedd4-2-/- Mice}

BAL studies demonstrated that the histological pneumonitis observed in congenital Nedd4-2 $2^{-/}$mice was accompanied by a dynamic polycellular inflammatory cell influx, as well as a mixed proinflammatory cytokine response. Assaying the BAL of 10-day-old and 3-week-old congenital Nedd4-2-/- mice revealed that the congenital deletion of Nedd4$2^{-/-}$produced an early (10 days) increase in the number of macrophages that demonstrated morphologic features of activation, including irregular shape, vacuolized cytoplasm and increased size, which was accompanied by increased acitiviy of matrix-metalloproteinase 12 (Mmp12) on the cell surface (Figure 3a-d), as previously described in Scnn1b-Tg mice with muco-obstructive lung disease [14,15]. Inflammatory parameters further increased by the age of 3 weeks, with elevated numbers of neutrophils and eosinophils (Figure 3e,f), as well as increased concentrations of KC, IL-13 and IL-1 $\beta$ (Figure 3g-i). 
a
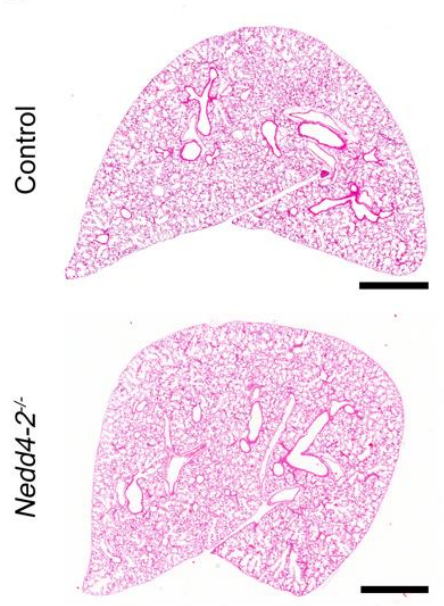

b
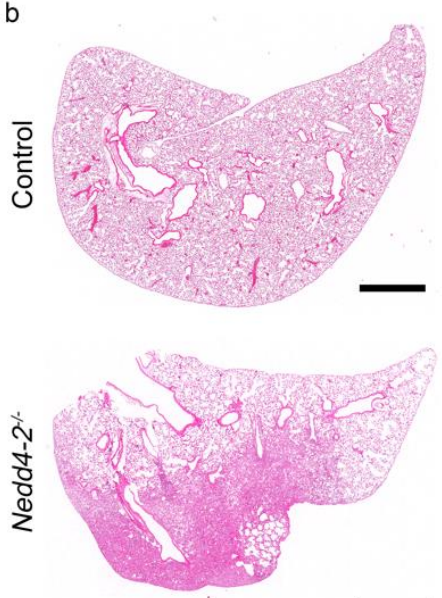
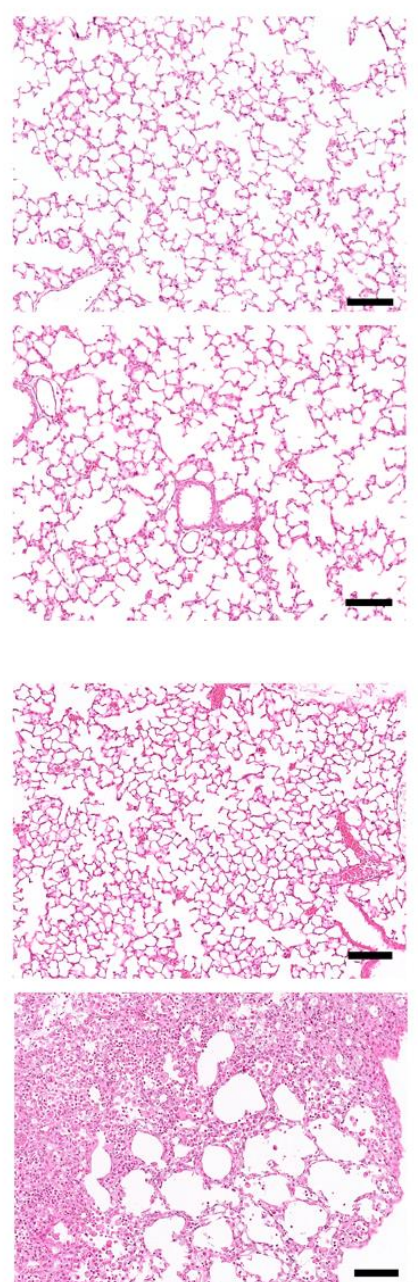
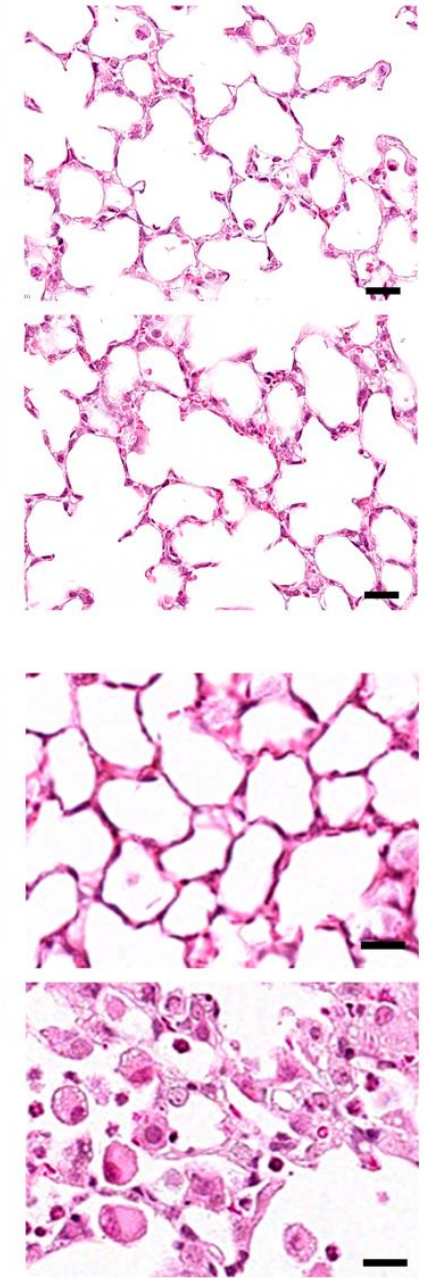

C
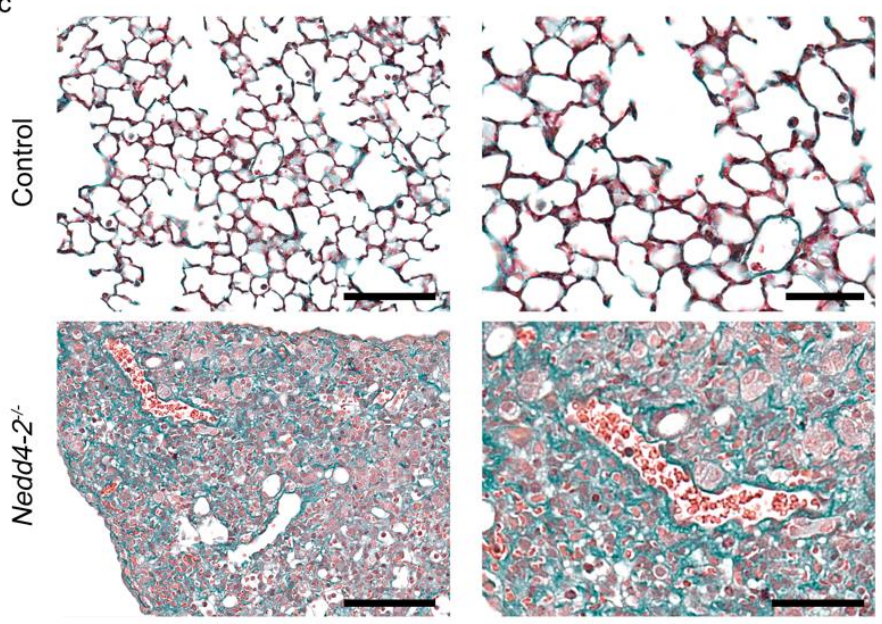

Figure 2. Congenital deletion of Nedd4-2 in lung epithelial cells causes alveolar inflammation and fibrosis in neonatal mice: $(\mathbf{a}, \mathbf{b})$ Representative micrographs of H\&E stained lung sections of 10-dayold (a) and 3-week-old (b) congenital Nedd4-2-/- and control mice. Scale bars, $1 \mathrm{~mm}$ (left column), $100 \mu \mathrm{m}$ (middle column) and $15 \mu \mathrm{m}$ (right column). (c) Masson-Goldner-Trichrome stained lung sections of 3-week-old congenital Nedd4-2-/- and control mice. Scale bars, $100 \mu \mathrm{m}$ (left column) and $50 \mu \mathrm{m}$ (right column). $n=7-10$ mice per group. 

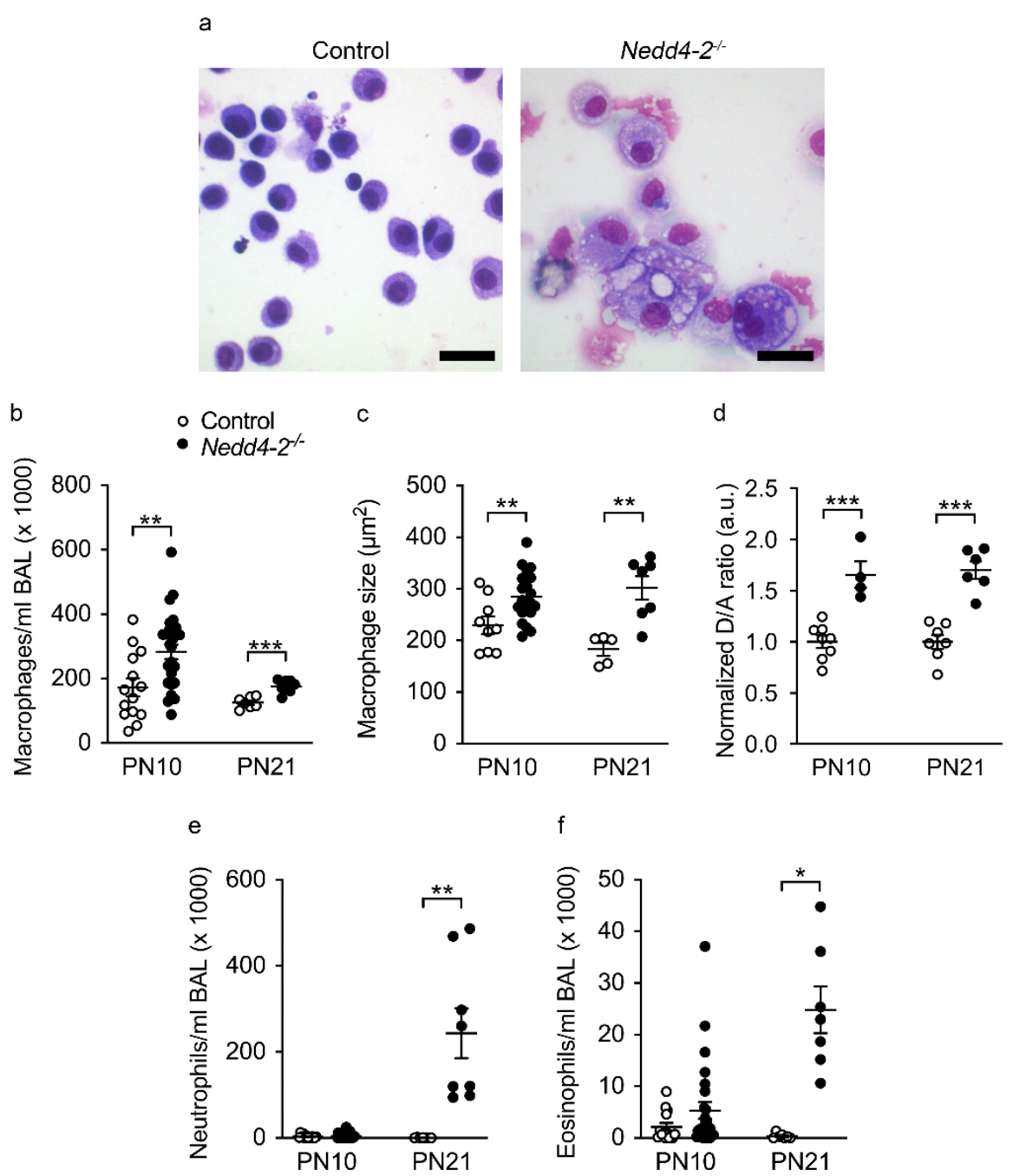

f

g

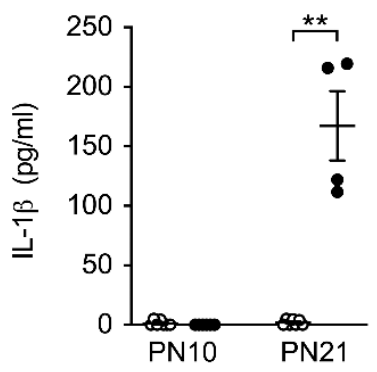

h

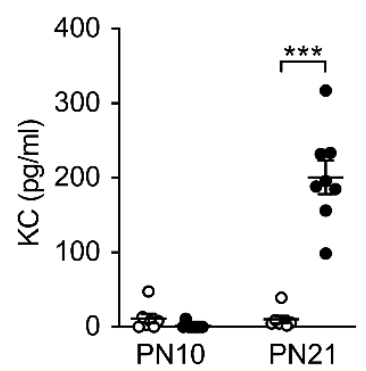

i

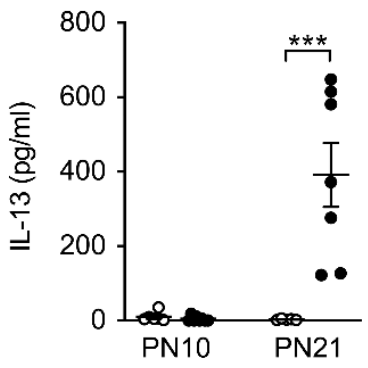

Figure 3. Development of pneumonitis in neonatal mice with congenital deletion of Nedd4-2: (a) Representative micrographs of BAL macrophages in 3-week-old congenital Nedd4-2 ${ }^{-/}$and control mice. Scale bars, $20 \mu \mathrm{m}$. (b,c) Number (b) and size (c) of macrophages in BAL. (d) Quantification of Mmp12 activity on the surface of BAL macrophages using the membrane-bound FRET reporter Laree1. Mmp12 activity was determined from the donor to acceptor (D/A) ratio of fluorescence emission produced by Mmp12-mediated cleavage of Laree1. Data were normalized to age-matched control mice. (e,f) Number of neutrophils (e) and eosinophils (f) in BAL of 10-day and 3-week-old congenital Nedd4-2-/- and control mice. (g-i) Concentrations of IL-1 $\beta$ (g), KC (h) and IL-13 (i) in BAL supernatant of 10-day and 3-week-old congenital Nedd4-2-/- and control mice. $n=4-27$ animals per group. ${ }^{*} p<0.05,{ }^{* *} p<0.01,{ }^{* * *} p<0.001$. Data are shown as mean \pm S.E.M. 
The observed inflammation in congenital Nedd4- $2^{-/-}$mice was not attributable to bacterial infection. Microbiological surveys of BAL of 3-week-old congenital Nedd4-2-/mice and littermate controls using bacterial cultures (Figure $4 \mathrm{a}, \mathrm{b}$ ), as well as $16 \mathrm{~S}$ rRNA PCR (Figure 4c), did not show any evidence of bacterial infection.

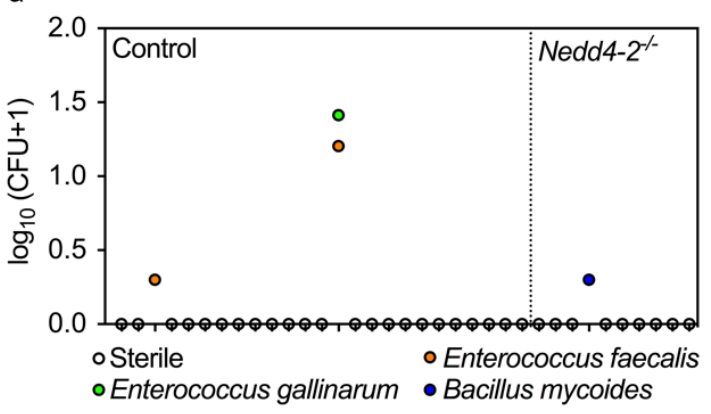

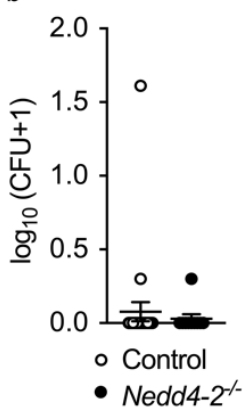

C

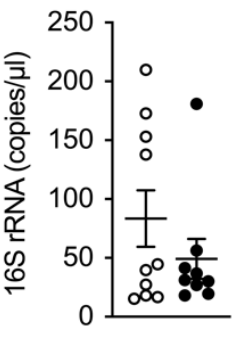

Figure 4. Bacterial species detected in BAL by bacterial culture and 16S rRNA quantitative PCR in neonatal mice with congenital deletion of Nedd4-2 and littermate controls: (a) Individual colony forming units (CFUs) for bacterial species cultured from BAL of 3-week-old congenital Nedd4-2-/mice and littermate controls. Each dot represents the result obtained from an individual mouse. (b) Summary of all CFUs in BAL of 3-week-old Nedd4-2-/- mice and littermate controls. (c) Bacterial load determined by $16 \mathrm{~S}$ rRNA analysis in BAL. $n=10-25$ mice per group. Data are shown as mean \pm S.E.M.

\subsection{Congenital Deletion of Nedd4-2 in Lung Epithelial Cells Causes Mucus Plugging and} Epithelial Necrosis in Distal and Terminal Airways in Neonatal Mice

Previous studies in adult mice with conditional deletion of Nedd4-2 identified epithelial remodeling of the distal airways with increased numbers of mucin-producing goblet cells, expression of Muc5b and impaired mucociliary clearance as key features of IPF-like lung disease in this model [9]. We therefore determined expression of the secreted mucins Muc5b and Muc5ac and mucus content in lungs of congenital Nedd4-2 ${ }^{-/-}$mice. Transcript levels of Muc5b and Muc5ac were increased in the lungs of 3-week-old congenital Nedd4-2 ${ }^{-1-}$ mice compared to controls (Figure 5a,b). Alcian blue-periodic acid-Schiff (AB-PAS) staining of lung sections showed goblet cell metaplasia and mucus plugging in the distal and terminal airways of 3-week-old congenital Nedd4-2-/- mice, especially in regions with a high grade of inflammation and fibrosis (Figure 5c), but not in age-matched littermate controls. Previous studies in Scnn1b-Tg mice and patients with muco-obstructive lung disease demonstrated that airway mucus plugging, probably via local hypoxia in the airway lumen, led to hypoxic degeneration and necrosis of airway epithelial cells [16-19]. Similarly, we found increased numbers of degenerative cells in the mucus-obstructed distal and terminal airways, especially in inflamed and fibrotic lung regions of 3-week-old congenital Nedd4-2 ${ }^{-/}$mice (Figure $5 \mathrm{~d}, \mathrm{e}$ ).

\subsection{Increased ENaC Activity in Freshly Excised Airway Tissues of Congenital Nedd4-2-1- Mice}

Nedd4-2 was shown to regulate cell surface expression of ENaC $[4,20]$, and our previous studies demonstrated that a lack of Nedd4-2 caused increased ENaC function, which led to airway surface liquid depletion and impaired mucociliary clearance in adult conditional Nedd4-2 $2^{-/}$mice [9]. To investigate the effects of the congenital deletion of Nedd4-2 on ENaC activity, we performed bioelectric Ussing chamber experiments in freshly excised tracheal tissue from 10-day-old neonatal mice. At postnatal day 10, i.e., prior to detectable histological changes, the $\mathrm{ENaC}$-mediated amiloride-sensitive short circuit current $\left(\mathrm{I}_{\mathrm{SC}}\right)$ was significantly increased in congenital Nedd4- $2^{-/-}$mice compared to littermate controls (Figure 6a,b), supporting a role of increased $\mathrm{ENaC}$ acitvity in the patohphysiology of the observed phenotype. 


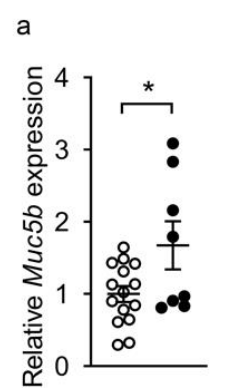

d b

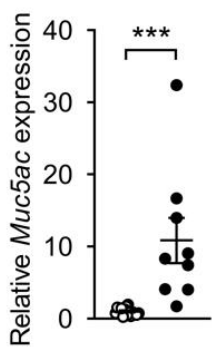

c

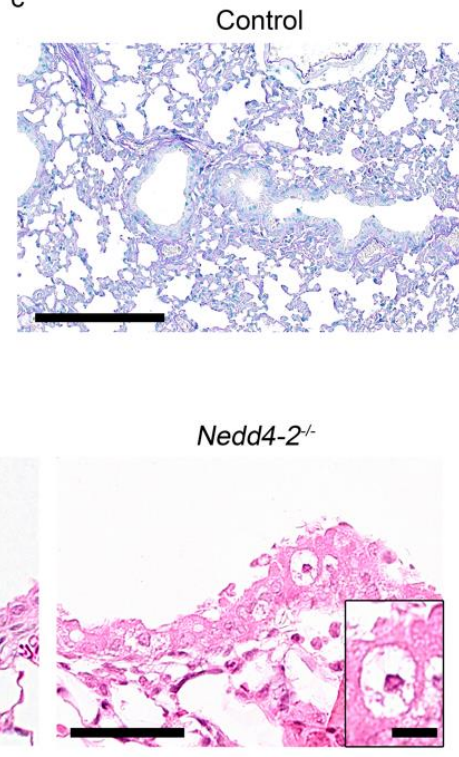

Nedd4-2/-

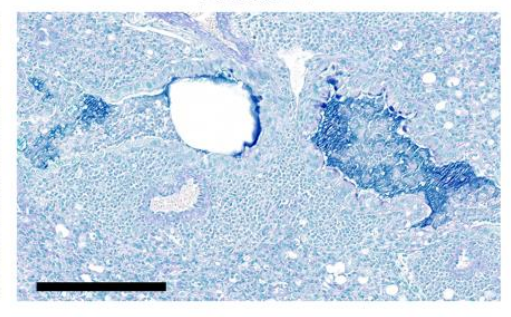

e

Figure 5. Congenital deletion of Nedd4-2 in lung epithelial cells causes mucus plugging and epithelial necrosis in distal and terminal airways of neonatal mice: (a,b) mRNA expression levels of Muc5b (a) and Muc5ac (b) in whole lungs from congenital Nedd4-2-/- and control mice. (c) Representative airway sections from 3-week-old congenital Nedd4-2 $2^{-/-}$and control mice stained with AB-PAS to illustrate the presence of mucus. Scale bars, $200 \mu \mathrm{m}$. (d) Representative H\&E stained lung sections of distal airways showing degenerative airway epithelial cells in 3-week-old congential Nedd4-2-/- mice. Scale bars, $50 \mu \mathrm{m}$ and $10 \mu \mathrm{m}$ (inset). (e) Summary of numeric densities of degenerative airway epithelial cells in congenital Nedd4-2 $2^{-/}$and control mice. $n=5-10$ mice per group. ${ }^{*} p<0.05,{ }^{* *} p<0.01,{ }^{* * *} p<0.001$. Data are shown as mean \pm S.E.M.

a

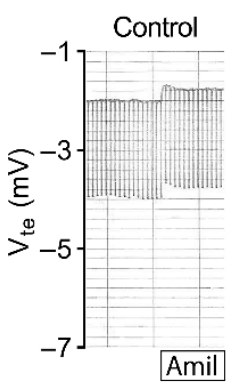

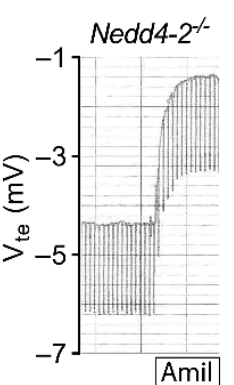

b

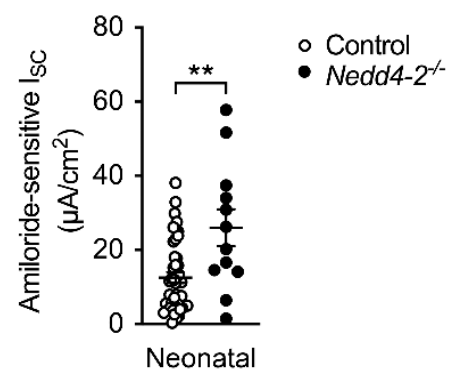

Figure 6. Increased ENaC activity in congenital Nedd4-2-/- mice: (a) Representative Ussing chamber recordings of the effect of amiloride (Amil) on transepithelial voltage $\left(V_{\text {te }}\right)$ and resistance $\left(R_{\text {te }}\right)$ of freshly excised tracheal tissues from a 10-day-old congenital Nedd4-2-/- mouse and a littermate control. (b) Summary of amiloride-sensitive short circuit current $\left(\mathrm{I}_{\mathrm{SC}}\right)$ across freshly excised airway tissues of 10-day-old congenital Nedd4-2-/- and control mice. $n=12-43$ mice per group. ${ }^{* *} p<0.01$. Data are shown as mean \pm S.E.M.

\section{6. proSP-C Is Mistrafficked in Lung Epithelial Cells of Congenital Nedd4-2-/- Mice}

Nedd4-2 was also shown to play a role in the posttranslational regulation of SP-C expressed in AT2 cells, and previous studies found mutations in the SFTPC gene in association with the development of ILD both in children (chILD) and in familial IPF in adults [21-26]. In our previous studies, we found that a lack of Nedd4-2 causes mistrafficking of proSP-C, but that this defect did not play a dominant role in determining the IPF-like lung phenotype produced by the conditional deletion of Nedd4-2 in adult mice [9]. To determine the impact of proSP-C mistrafficking due to lack of Nedd4-2 in the neonatal lung, we performed biochemical studies and investigated the effect of the genetic deletion of Sftpc in congenital Nedd4-2-/- mice. 
Using double label fluorescence immunohistochemistry for proSP-C and Lamp-1, we found that, in 3-week-old neonatal control mice, the subcellular distribution of proSP-C was predominantly found in Lamp-1 positive lamellar bodies. In the lungs of 3-weekold congenital Nedd4-2-/- mice, similar to our findings in adult conditional Nedd4-2-/mice [9], a significant proportion of proSP-C expression shifts to Lamp-1 negative cytosolic compartments (Figure 7a). The mistrafficking of proSP-C was accompanied by marked changes in its posttranslational processing. Western blots of proSP-C from lung homogenates of 3-week-old mice revealed a 21-22 kDa proSP-C doublet in control mice while, in congenital Nedd4-2 ${ }^{-/-}$mice, the primary translation product doublet shifts to a single band, accompanied by the appearance of a new intermediate around 16 or $17 \mathrm{kDa}$ (Figure $7 \mathrm{~b}$ ). In BAL, Western blotting revealed a reduction in mature SP-C in 3-week-old congenital Nedd4-2-/- mice compared to littermate controls (Figure 7c). Despite a major impact on SP-C biosynthesis, other components of the surfactant system, such as surfactant protein B and D (SP-B and SP-D), were largely unaffected (Figure 7b).

a
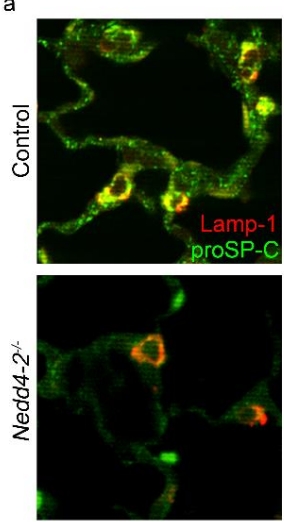

d

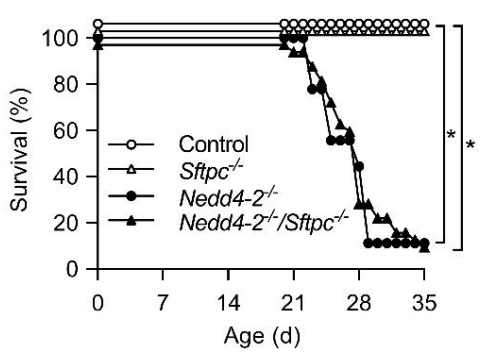

$\mathrm{f}$

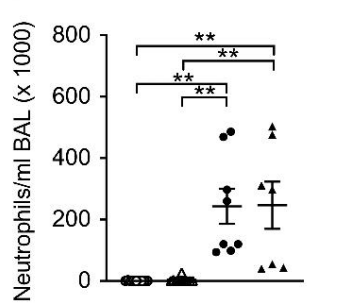

prosP-C

$$
\text { SP-B }
$$

SP-D

Actb

BAL

mature SP-C
Control- $-N e d d 42^{--}$

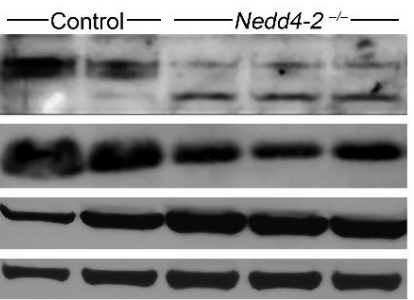

C $\longrightarrow$ Control $-\longrightarrow$ Nedd $4-2^{-+}-$
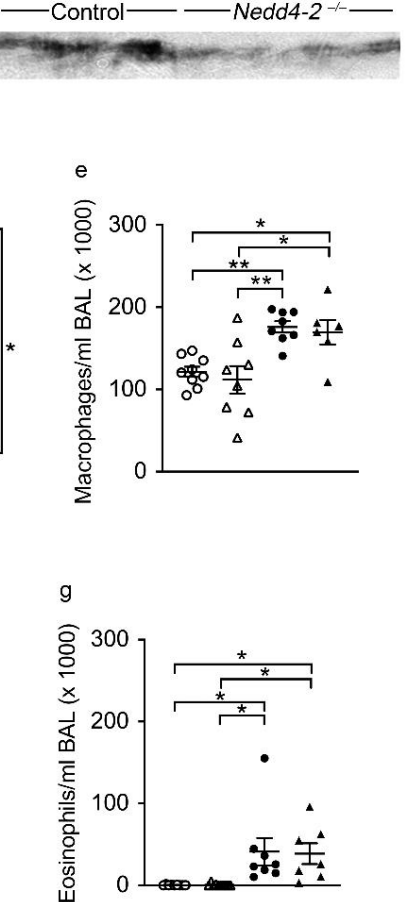

Figure 7. Evidence of proSP-C mistrafficking in lung epithelial cells of congenital Nedd4-2-/- mice: (a) Representative confocal images of double label fluorescence immunohistochemistry for proSP-C (green) and Lamp-1 (red). (b) Western blots for proSP-C, SP-B and SP-D from lung homogenates of 3-week-old congenital Nedd4-2-/- and control mice. (c) Western blots for mature SP-C in BAL of 3-week-old congenital Nedd4-2-/- and control mice. (d) Survival curve of congenital Nedd4-2-/-, congenital Nedd4-2-/- $/ \mathrm{Stpc}^{-/-}$, littermate $\mathrm{Sftpc}^{-/-}$and control mice. $n=9-32$ mice per group. ${ }^{*} p<0.05$. (e-g) Number of macrophages (e), neutrophils (f) and eosinophils (g) in BAL of 3-week-old congenital Nedd4 $-2^{-/-}$, congenital Nedd4-2-/- $/ \mathrm{Sftpc}^{-/-}$, littermate $S \mathrm{ftpc} \mathrm{c}^{-/-}$and control mice. $n=7-9$ mice per group. ${ }^{*} p<0.05,{ }^{* *} p<0.01$. Data are shown as mean \pm S.E.M. 
Despite in vivo confirmation of the previously described role for NEDD4-2 in SFTPC biosynthesis [1,2], and similar to our previous studies in adult conditional Nedd4-2-/mice [9], we found that proSP-C mistrafficking alone was insufficient to drive the abnormal lung phenotype found in neonatal mice with the congenital deletion of Nedd4-2. When Nedd4-2 $2^{f l f l} / C C S P-r t T A 2^{S}-M 2 / L C 1$ mice were crossed with Sftpc-deficient $\left(S f t p c^{-1-}\right.$ ) mice and induced in utero with doxycycline, the genetic deletion of Sftpc in quadruple transgenic mice had no effect on survival (Figure 7d), the number of BAL macrophages (Figure 7e), neutrophils (Figure 7f), eosinophils (Figure 7g) or on structural lung disease (data not shown) compared to triple transgenic congenital Nedd4-2-/- mice. These data are consistent with our previous results in adult conditional Nedd4-2 ${ }^{-/-}$mice, and imply that congenital Nedd4-2 deficiency imparts a toxic effect that is not attributable to a single protein but more likely caused by pleiotropic effects on AT2 cell homeostasis.

\section{Discussion}

This study demonstrates that the congenital deletion of Nedd4-2 in lung epithelial cells causes a spontaneous and rapidly progressive lung disease in neonatal mice that shares key clinical and histopathological features of interstitial lung diseases in children (chILD), and thereby extends recent reports on the E3 ubiquitin ligase NEDD4-2 in the pathogenesis of ILD [9]. These features include respiratory distress, hypoxemia, growth failure, sterile alveolitis, patchy fibrotic remodeling of the alveolar airspaces and high neonatal mortality (Figures 1-4) [27,28]. Similar to conditional deletion in adult mice [9], we found that the congenital deletion of Nedd4-2 results in increased expression of the mucins Muc5b and Muc5ac and a remodeling of the distal airways including goblet cell metaplasia in congenital Nedd4-2-/- mice (Figure 5). In addition, epithelial defects previously reported in adult conditional Nedd4-2-/- mice, such as increased ENaC-mediated $\mathrm{Na}^{+} /$fluid transport and abnormal proSPC trafficking, were confirmed in the lungs of neonatal congenital Nedd4-2 ${ }^{-/-}$mice (Figures 6 and 7) [9]. Taken together, these results demonstrate that Nedd42 in lung epithelial cells plays an important role in normal lung development, provide additional evidence for its importance in lung health and have established a mouse model of chILD, comprising a spectrum of lung diseases in children with high unmet need.

Besides the important similarities of pulmonary phenotypes caused by the congenital vs. the conditional deletion of Nedd4-2 in the murine lung, including restrictive lung disease with patchy fibrotic remodeling of distal airspaces due to dysregulated Smad2/3 signaling, leading to increased levels of TGF $\beta$, remodeling of distal airways with goblet cell metaplasia and increased expression of $M u c 5 b$, as well as high pulmonary mortality (Figures 1,2 and 5) [9,29], our study also revealed some striking age-dependent differences. First, the onset and progression of ILD was substantially accelerated in congenital vs. conditional Nedd4-2-/- mice, as evidenced by the time point of mortality that occurred within $\sim 4$ weeks after birth in most neonatal congenital Nedd4- $2^{-/-}$mice compared to $\sim 4$ months after conditional deletion of Nedd4-2 ${ }^{-/}$in adult mice (Figure 1) [9]. Second, alveolitis with inflammatory cell infiltrates, including morphologically activated "foamy" macrophages, neutrophils and eosinophils associated with elevated pro-inflammatory cytokines such as IL-1 $\beta, \mathrm{KC}$ and IL-13 in BAL, was substantially more prominent in neonatal congenital Nedd4-2 ${ }^{-/-}$compared to conditional Nedd4- $2^{-/-}$mice (Figure 3) [9]. Third, histopathologic studies of the lungs of congenital Nedd4-2 $2^{-/}$mice revealed mucus plugging of the distal airways that was associated with hypoxic epithelial necrosis (Figure 5), a phenotype that was previously reported in neonatal Scnn1b-Tg mice with muco-obstructive lung disease [16-19], but not observed in adult conditional Nedd4-2 ${ }^{-/}$mice [9].

Based on these findings, we studied the role of pro-SPC trafficking in AT2 cells and ENaC-mediated $\mathrm{Na}^{+}$transport across freshly excised airway tissues of neonatal congenital Nedd4- $2^{-/}$mice, i.e., epithelial cell functions that we previously found to be abnormal in adult conditional Nedd4-2 ${ }^{-/}$mice, as a potential explanation for these age-dependent differences in lung phenotypes. Using a variety of techniques, our data provide evidence of defective proSP-C trafficking, maturation and secretion in this neonatal model (Figure 7), 
which parallels findings we reported in adult conditional Nedd4-2 $2^{-/}$mice [9]. However, similar to adult conditional Nedd4-2 $2^{-/}$mice, the genetic deletion of Sftpc was insufficient to rescue the lung disease phenotype in congenital Nedd4- $2^{-/}$mice (Figure 7) [9]. Thus, the effect size of neither misprocessed proSP-C nor loss of mature SP-C in surfactant is sufficient to drive the ILD phenotype and explain the age-dependent differences observed in neonatal congenital vs. adult conditional Nedd4-2-/- mice.

Similar to previous studies in adult conditional Nedd4-2-/- mice [9], we show that congenital deletion of Nedd4-2 produces increased $\mathrm{ENaC}$ activity in airway epithelial cells of neonatal mice (Figure 6). In adult conditional Nedd4-2-/- mice, we demonstrated that increased $\mathrm{ENaC}$-mediated $\mathrm{Na}^{+}$/ fluid absorption across airway epithelia, as previously shown in patients with cystic fibrosis and Scnn1b-Tg mice [6,30-33], results in airway surface liquid depletion and impaired mucociliary clearance [9]. As mucociliary clearance is an important innate defense mechanism of the lung, and retention of inhaled irritants and pathogens leads to repeated micro-injury and chronic inflammation, our data support mucociliary dysfunction as an important disease mechanism triggering ILD in both congenital and adult conditional Nedd4-2-/- mice $[9,32,34,35]$. Of note, this concept is consistent with studies in $M u c 5 b$-overexpressing mice that exhibit impaired mucociliary clearance and develop more severe bleomycin-induced pulmonary fibrosis [36]. The importance of dysregulated $\mathrm{ENaC}$ activity in the pathogenesis of ILD in congenital Nedd4-2 $2^{-/}$mice is also supported by the observation that this epithelial ion transport defect was already present in 10-day-old mice with normal lung morphology, i.e., prior to the onset of histological signs of ILD (Figure 2), as well as previous studies in Nedd4-2flffl $/$ ftpc-rtTA/Cre mice with the constitutive deletion of Nedd4-2 under control of the SP-C promoter [11] and mice with the constitutive overexpression of the $\alpha$ and $\beta$ subunits of $\mathrm{ENaC}$ in the lung [37]. In both models, increased $\mathrm{ENaC}$ activity in the distal lung was associated with severe pulmonary inflammation, mucus obstruction of distal airways and high neonatal mortality $[11,37]$. Taken together, these data support increased ENaC activity leading to airway/alveolar surface liquid depletion and mucociliary dysfunction in distal airways as a key pathogenetic mechanism of ILD in congenital Nedd4-2-/- mice.

Interestingly, a previous study in fetal distal lung epithelial cells of wild-type rats found that the male sex is associated with reduced ENaC-mediated $\mathrm{Na}^{+}$transport [38] Our study included all newborns from each litter, resulting in a balanced distribution of male and female neonates that enabled an exploratory analysis of potential gender differences. Similar to previous studies in rat lung epithelia [38], we observed a $\sim 30 \%$ reduction in ENaC-mediated $\mathrm{Na}^{+}$absorption in male vs. female mice in the control group, as well as the congenital Nedd4-2-/- group (data not shown). However, this gender difference in $\mathrm{ENaC}$ function did not reach statistical significance based on the number of mice available for our study. Similar, other pulmonary phenotypes of neonatal congenital Nedd4-2 ${ }^{-/-}$mice including hypoxemia, growth failure, pulmonary inflammation, mucin expression, epithelial cell necrosis, abnormal proSP-C trafficking and mortality did not differ between male vs. female mice. However, our study was not powered to detect gender differences, and future studies are necessary to determine the potential role of gender differences in $\mathrm{ENaC}$-mediated $\mathrm{Na}^{+}$absorption in the pathogenesis of lung disease in congenital Nedd4-2-/- mice.

Several factors may explain the age-specific differences in pulmonary phenotypes produced by deletion of Nedd4-2 in neonatal vs. adult mice. First, the accelerated onset and increased severity of pulmonary inflammation observed in congenital Nedd4-2 ${ }^{-/-}$mice may be explained by an increased susceptibility of the neonatal lung to the retention of inhaled irritants, as previously shown for cigarette smoke exposure in Scnn $1 b$-Tg mice with muco-obstructive lung disease [39]. Second, in congenital Nedd4-2-/- mice, we found that increased $\mathrm{ENaC}$ activity leading to mucociliary dysfunction, probably due to a smaller diameter of neonatal vs. adult airways, is associated with mucus plugging and hypoxic epithelial cell necrosis of the distal airways (Figure 5), whereas this phenotype was not observed in conditional Nedd4-2 $2^{-/}$mice [9]. As hypoxic epithelial cell necrosis in mucus- 
obstructed airways has been identified as a strong trigger of sterile inflammation via triggering the pro-inflammatory IL-1 signaling pathway in the absence of bacterial infection in Scnn1b-Tg mice, and patients with muco-obstructive lung diseases such as cystic fibrosis and chronic obstructive pulmonary disease [16,40-42], this mechanism may also contribute to the more severe inflammatory phenotype caused by the congenital deletion of Nedd4-2 in the neonatal lung. Finally, the differences in the onset and progression of ILD in congenital vs. conditional Nedd $4-2^{-/}$mice may be explained by age-dependent differences in the temporal and spatial activity of the CCSP promoter observed in previous studies of the $C C S P-r t T A 2^{S}-M 2$ activator line that was used for inducible lung-specific deletion of Nedd4-2 [9,12]. These studies demonstrated a broader expression of the reverse tetracycline transactivator $\mathrm{rtTA}^{\mathrm{S}}$-M2 in AT2 cells, as well as club cells throughout the conducting airways of the neonatal lung whereas, in adult mice $\mathrm{rtTA}_{2} \mathrm{~S}-\mathrm{M} 2$ expression was more restricted to AT2 cells and club cells of the distal airways [12]. In addition, a previous study demonstrated age-dependent activity of the CCSP promoter, with the highest levels around birth and decreasing activity in older mice [43]. These temporal and spatial differences are expected to result in a faster and more widespread deletion of Nedd4-2 in the neonatal vs. adult lung that may aggravate increased $\mathrm{ENaC}$ activity and mucociliary dysfunction, increased pro-fibrotic TGF $\beta$ signaling and potentially other pathogenic processes induced by Nedd4-2 deficiency [1-3,8-11,44-49]; therefore, they might also contribute to the more rapid onset and progression of ILD in congenital vs. conditional Nedd4-2-/- mice.

Previous studies demonstrated that systemic deletion of Nedd4-2 leads to perinatal lethality in mice and loss-of-function variants of NEDD4-2 have not been described in humans [10]. In our study, targeted in utero deletion of Nedd4-2 in lung epithelial cells did not cause perinatal morbidity or mortality, as evidenced by a normal distribution of genotypes and as expected from Mendelian ratios, normal development and weight gain, as well as a lack of respiratory symptoms in the the first 10 days of life (Figures 2, 3 and A2). However, our data demonstrate that the congenital deletion of Nedd4-2 in the lung leads to an early onset and rapid progression of ILD beyond the perinatal period (Figures 1-3). In our previous study, we found that NEDD4-2 protein and transcript levels were reduced in lung tissue biopsies from IPF patients, supporting the role of NEDD4-2 dysfunction in human ILD [9]. Based on these findings in adult IPF patients, we speculate that NEDD4-2 deficiency may also be implicated in the pathogenesis of chILD. However, future studies are necessary to test this hypothesis and determine mechanisms of lung-specific NEDD4-2 deficiency that may be caused, e.g., by transcriptional, post-transcriptional or epigenetic regulation of NEDD4-2 in the lung.

In summary, our results demonstrate that the congenital deletion of Nedd4-2 in lung epithelial cells causes severe ILD in neonatal mice that shares key features with interstitial lung diseases in children (chILD), including respiratory distress, hypoxemia, growth failure, sterile alveolitis, progressive fibrotic remodeling of the lung parenchyma and high mortality. These data further substantiate an important role of Nedd4-2 in normal lung development and lung health, and have established a mouse model of chILD that may serve as a useful tool for studies of the complex in vivo pathogenesis, the identification of biomarkers and therapeutic targets, as well as preclinical evaluations of novel therapeutic strategies that are urgently needed to improve the clinical outcome of patients with chILD [13].

\section{Materials and Methods}

\subsection{Experimental Animals}

All animal studies were approved by the animal welfare authority responsible for the University of Heidelberg (Regierungspräsidium Karlsruhe, Karlsruhe, Germany). Mice for congenital deletion of Nedd4-2 in lung epithelial cells were generated as previously described [9]. In brief, mice carrying Nedd4-2flffl [11] were intercrossed with CCSP-rtTA2 $2_{\text {- }}$ M2 line 38 (CCSP-rtTA2 $\left.{ }^{S}-M 2\right)$ [12] and LC1 mice [50,51]. All three lines were on a C57BL6/N background. $\mathrm{Stpc}^{-/-}$mice [52] were obtained on a $129 \mathrm{S6}$ background. Mice were housed in a specific pathogen-free animal facility and had free access to food and water. For prenatal 
induction, dams were treated continuously with doxycycline from the first day of mating and mice were studied at 10 days and 3 weeks of age. All newborn mice of a litter were included in our study, irrespective of gender and genotype, yielding a balanced gender distribution in the control groups and congenital Nedd4-2 $2^{-1-}$ groups. Details on the genotype distribution are provided in Figure A2, Appendix A.

\subsection{Measurement of Inflammatory Markers in BAL}

BAL was performed and differential cell counts and macrophage sizes were determined as previously described [17]. Concentrations of KC (CXCL-1) and IL-13 were measured in cell-free BAL supernatant and IL- $1 \beta$ was measured in total lung homogenates by ELISA (R\&D Systems, Minneapolis, MN, USA) according to manufacturer's instructions. Mmp12 acitivity on the surface of BAL macrophages was assessed by a Foerster resonance energy transfer (FRET) based activity assay as previously described [14]. In brief, BAL cells were incubated for $10 \mathrm{~min}$ at room temperature with the membrane-anchored FRET reporter Laree1 $(1 \mu \mathrm{M})$. Cells were diluted with PBS to a volume of $200 \mu \mathrm{L}$ and centrifuged on slides by cytospin. Membrane-bound Mmp12 activity was measured by confocal microscopy. Images were acquired on a Leica SP8 confocal microscope with an HC PL APO CS2 63× 1.3 oil objective (Leica microsystems, Wetzlar, Germany). Donor/acceptor ratio was calculated using the open source imaging analysis software Fiji version 1.46r [53,54].

\subsection{Histology and Morphometry}

Right lungs were inflated with $4 \%$ buffered formalin to $25 \mathrm{~cm}$ of fixative pressure. Noninflated left lungs were immersion fixed. Lungs were paraffin embedded and sectioned at $5 \mu \mathrm{m}$ and stained with H\&E, Masson-Goldner-Trichrome and AB-PAS. Images were captured with a NanoZoomer S60 Slidescanner (Hamamatsu, Hamamatsu City, Japan) at a magnification of $40 \times$. Airway regions were determined from proximal-to-distal distances and airway branching, as determined by longitudinal sections of lung lobes at the level of the main axial airway, as previously described [55]. Degenerative cells were identified by morphologic criteria such as swollen cells with vacuolized cytoplasm and pycnotic nucleus in H\&E stained lung sections. Numeric cell densities were determined using NDP.view2 software version 2.7.52 (Hamamatsu, Hamamatsu City, Japan), as previously described [16].

\subsection{Pulse Oximetry}

Oxygen saturation of 3-week-old mice was determined using a noninvasive pulse oximeter for laboratory animals (MouseOx ${ }^{\circledR}$ Plus, Starr Life Science, Oakmont, PA, USA) and measured with a thigh clip sensor, as previously described [9]. Percent oxygen saturation was measured after stabilization of heart rate and breathing frequency.

\subsection{Immunofluorescence Microscopy}

Lung sections were evaluated for proSP-C using a primary polyclonal anti-NproSP-C antibody and Alexa Fluor 488 conjugated goat anti-rabbit IgG (Jackson Immuno Research, 111-545-062, West Grove, PA, USA), as described previously [24]. Confocal images were acquired using a $488 \mathrm{~nm}$ laser line package of an Olympus Fluoview confocal system attached to an Olympus IX81 microscope (60× oil objective).

\subsection{SDS-PAGE and Immunoblotting}

Sodium dodecyl sulfate polyacrylamide gel electrophoresis (SDS-PAGE) using Novex Bis-Tris gels (NP0301, ThermoFisher Scientific, Waltham, MA, USA) and immunoblotting of PVDF membranes with primary antisera followed by species specific horseradish peroxidase conjugated secondary antisera was performed as published [24,56]. Bands detected by enhanced chemiluminescence (ECL2, ThermoFisher Scientific, 80196, Waltham, MA, USA; or WesternSure, LI-COR, 926-95000, Lincoln, NE, USA) were acquired by exposure to film or direct scanning using an LI-COR Odyssey Fc Imaging Station (Lincoln, NE, USA) 
and quantitated using the manufacturer's software. For immunoblotting of surfactant proteins, the following antisera were used. Polyclonal anti- NproSP-C raised against the Met [10]-Glu [23] domain of rat proSP-C peptide, polyclonal anti-SP-B (PT3) raised against purified bovine SP-B and polyclonal anti-SP-D (antisera 1754) raised against 2 synthetic SP-D peptides were each produced in rabbits in house and validated as published [56-59]. Polyclonal mature anti-SP-C antisera was obtained from Seven Hills Bioreagents (WRAB76694; Cincinnati, OH, USA) and validated in a prior study [24]. Monoclonal anti-Actb was obtained from Sigma Aldrich (A1978) St. Louis, MO, USA.

\subsection{Electrogenic Ion Transport Measurements}

Mice were deeply anesthetized via intraperitoneal injection of a combination of ketamine and xylazine $(120 \mathrm{mg} / \mathrm{kg}$ and $16 \mathrm{mg} / \mathrm{kg}$, respectively) and killed by exsanguination. Airway tissues were dissected using a stereomicroscope as previously described $[60,61]$ and immediately mounted into perfused micro-Ussing chambers. Experiments were performed at $37^{\circ} \mathrm{C}$ under open-circuit conditions and amiloride-sensitive ENaC-mediated short circuit current ( $\mathrm{I}_{\mathrm{SC}}$ ) was determined as previously described [61].

\section{8. mRNA Expression Analysis}

Lungs from mice were stored at $4{ }^{\circ} \mathrm{C}$ in RNAlater (Applied Biosystems, Darmstadt, Germany). Total RNA was extracted using Trizol reagent (Invitrogen, Karlsruhe, Germany) according to manufacturer's instructions. cDNA was obtained by reverse transcription of $1 \mu \mathrm{g}$ of total RNA with Superscript III RT (Invitrogen, Karlsruhe, Germany). To analyze mRNA expression of mucins, quantitative real-time PCR was performed on an Applied Biosystems 7500 Real Time PCR System using TaqMan universal PCR master mix and the following inventoried TaqMan gene expression assays for $\mathrm{Muc5b}$ (Accession No. NM_028801.2; Taqman ID Mm00466391_m1) and Muc5ac (Accession No. NM_010844.1; Taqman ID Mm01276718_m1) (Applied Biosystems, Darmstadt, Germany) according to manufacturer's instructions. Relative fold changes of target gene expression were determined by normalization to expression of the reference gene Actb (Accession No. NM_007393.1; Taqman ID Mm00607939_s1) [17,62].

\subsection{Microbiology Studies}

BAL was performed in 3-week-old mice under sterile conditions. Mice were deeply anesthetized via intraperitoneal injection with a combination of ketamine and xylazine $(120 \mathrm{mg} / \mathrm{kg}$ and $16 \mathrm{mg} / \mathrm{kg}$, respectively) and killed by exsanguination. A cannula was inserted into the trachea and whole lungs were lavaged 3 times with $300 \mu \mathrm{L}$ PBS. The recovered BAL fluid was plated on columbia blood agar (Becton Dickinson, Heidelberg, Germany), chocolate agar, Mac Conkey agar, prereduced Schaedler agar and kanamycinvancomycin blood agar plates (bioMérieux, Nürtingen, Germany). After $48 \mathrm{~h}$ of incubation at $37^{\circ} \mathrm{C}$, colony forming units were counted and classified by MALDI-TOF massspectrometry (Bruker Daltonik, Bremen, Germany). Then, 16S rRNA PCR was performed to detect non-culturable bacterial species [63].

\subsection{Statistical Analysis}

All data are shown as mean \pm S.E.M. Data were analyzed with GraphPad Prism version 7 (GraphPad Software Inc, LaJolla, CA, USA). Distribution of data was assessed with Shapiro-Wilk test for normal distribution. For comparison of two groups, unpaired two-tailed t-test or Mann-Whitney test were used as appropriate. Comparison of more than two groups with normally distributed data was performed with one-way ANOVA followed by Tukey's post hoc test. Genotype frequency was analyzed by $\chi^{2}$ test. Comparison of survival was evaluated using the log rank test. A $p$ value $<0.05$ was accepted to indicate statistical significance.

Author Contributions: Conceptualization, D.H.W.L., J.D., S.M., A.S.A., S.Z., H.K., A.H.D., M.F.B. and M.A.M.; methodology, D.H.W.L., J.D., S.M., A.S.A., S.Z., H.K., A.H.D., M.F.B. and M.A.M.; 
formal analysis, D.H.W.L., J.D., S.M., A.S.A., S.Z., H.K., A.H.D., M.F.B. and M.A.M.; investigation, D.H.W.L., J.D., S.M., A.S.A., S.Z., H.K., A.H.D., M.F.B. and M.A.M.; writing-original draft preparation, D.H.W.L., J.D., S.M., A.S.A., S.Z., H.K., A.H.D., M.F.B. and M.A.M.; supervision, M.A.M.; funding acquisition, H.K., M.F.B. and M.A.M. All authors have read and agreed to the published version of the manuscript.

Funding: This project was supported by grants from the German Ministry for Education and Research (82DZL004A1 and 82DZL009B1 to M.A.M.), the Deutsche Forschungsgemeinschaft (DFG, German Research Foundation-SFB-TR84 B08, SFB 1449 A01, C04 and Z02, and project no. 450557679 to M.A.M. and KA3423/3-1 to H.K.), VA Merit Review (1I01BX001176 to M.F.B.), the National Institutes of Health (R01 HL145408 and U01 HL 152970 to M.F.B.), JSPS KAKENHI (Grant Numbers JP15K21769 and JP20K07334 to H.K.), Ohsumi Frontier Science Foundation (to H.K.), and the Takeda Science Foundation (to H.K.).

Institutional Review Board Statement: All animal studies were approved by the Regierungspräsidium Karlsruhe, Germany. Project identification number 35-9185.81/G-45/14, august 2014.

Informed Consent Statement: Not apllicable.

Data Availability Statement: The data presented in this study are available on request from the corresponding author.

Acknowledgments: We thank N. Brose (Max Planck Institute of Experimental Medicine, Goettingen) for providing Nedd4-2 $2^{f l f l}$ mice, S. W. Glasser (Cincinnati Children's Hospital Medical Center, Cincinnati, OH, USA) for providing $\mathrm{Sftpc}^{-/-}$mice and J. Schatterny, S. Butz (University of Heidelberg), and Scott J. Russo (University of Pennsylvania, Pennsylvania, PA, USA) for expert technical assistance.

Conflicts of Interest: The authors declare no conflict of interest.

\section{Appendix A}

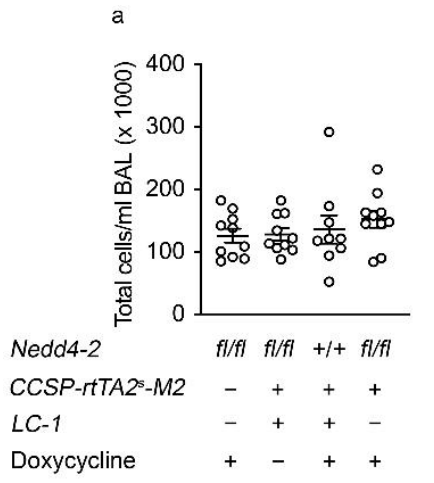

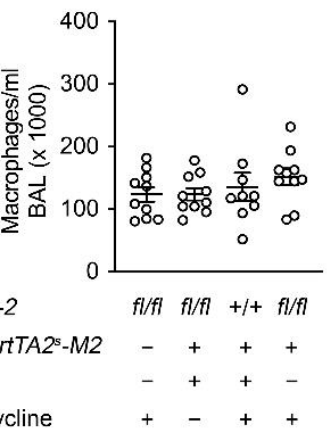

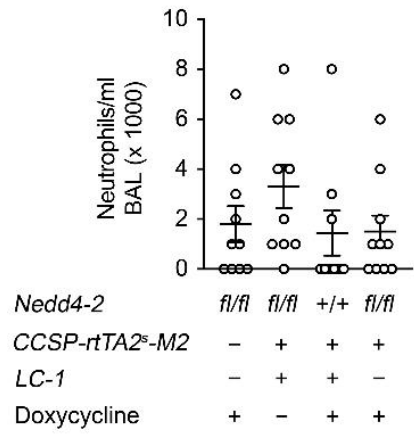

d

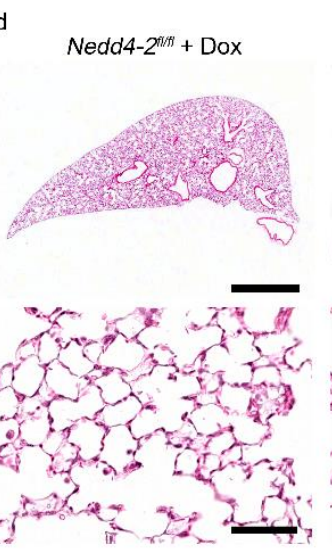

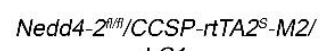

Nedd4-2+it/ CCSP-rTA2 $-M 2 / L C 1+$ Dox

Nedd4-2titit/CCSP-rtTA2s-M2 LC1
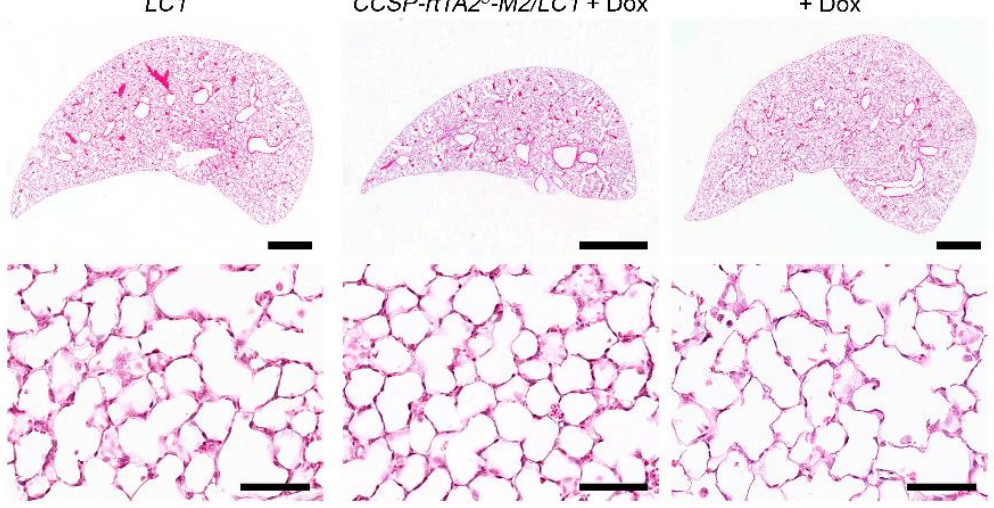

Figure A1. Pulmonary phenotypes of 3-week-old mice used as controls: (a-d) Total cell counts (a), number of macrophages (b) and neutrophils (c) in BAL and representative morphology of H\&E stained 
lung sections (d) in mice with the different genotypes that served as controls to exclude potential off-target effects of the expression system. Dams were treated with doxycycline from the start of mating and offspring was studied 3 weeks after birth. Upper row, scale bars, $1 \mathrm{~mm}$. Lower row, scale bars, $50 \mu \mathrm{m} . n=9-10$ mice per group. Data are shown as mean \pm S.E.M.

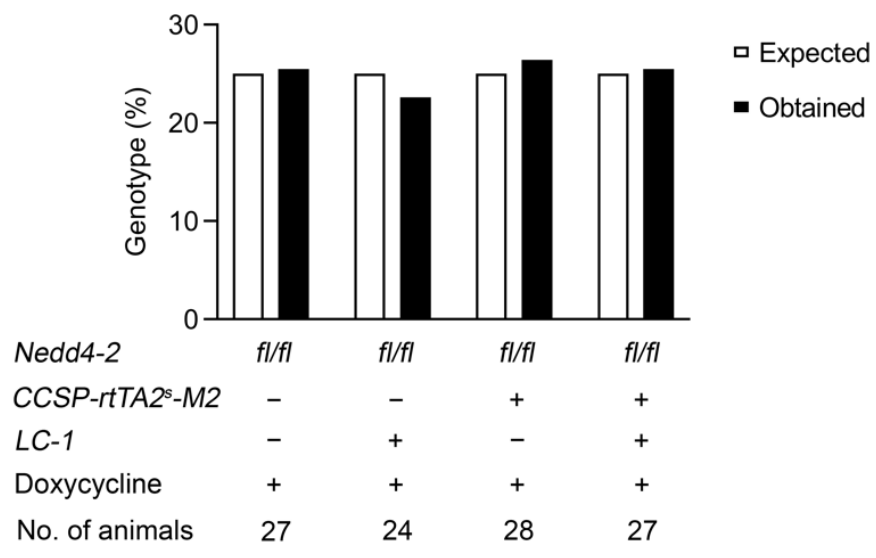

Figure A2. Congenital deletion of Nedd4-2 does not affect perinatal survival: Distribution of genotypes in 10-day-old mice from the intercross of doxycycline-induced Nedd4-2 fl/fl $/ C C S P-r t T A 2 S-M 2$ and Nedd4-2flfl/LC1 mice. All genotypes are represented as expected from Mendelian ratios. $n=$ 106 mice from 14 litters.

\section{References}

1. Kotorashvili, A.; Russo, S.J.; Mulugeta, S.; Guttentag, S.; Beers, M.F. Anterograde Transport of Surfactant Protein C Proprotein to Distal Processing Compartments Requires PPDY-mediated Association with Nedd4 Ubiquitin Ligases. J. Biol. Chem. 2009, 284, 16667-16678. [CrossRef] [PubMed]

2. Conkright, J.J.; Apsley, K.S.; Martin, E.P.; Ridsdale, R.; Rice, W.R.; Na, C.-L.; Yang, B.; Weaver, T.E. Nedd4-2-Mediated Ubiquitination Facilitates Processing of Surfactant Protein-C. Am. J. Respir. Cell Mol. Biol. 2010, 42, 181-189. [CrossRef] [PubMed]

3. Gao, S.; Alarcon, C.; Sapkota, G.; Rahman, S.; Chen, P.Y.; Goerner, N.; Macias, M.J.; Erdjument-Bromage, H.; Tempst, P.; Massague, J. Ubiquitin ligase Nedd4L targets activated Smad2/3 to limit TGF-beta signaling. Mol. Cell 2009, 36, 457-468. [CrossRef]

4. Rotin, D.; Staub, O. Nedd4-2 and the Regulation of Epithelial Sodium Transport. Front. Physiol. 2012, 3. [CrossRef]

5. Mall, M.A. ENaC inhibition in cystic fibrosis: Potential role in the new era of CFTR modulator therapies. Eur. Respir. J. 2020, 56, 2000946. [CrossRef]

6. Mall, M.A.; Button, B.; Johannesson, B.; Zhou, Z.; Livraghi, A.; Caldwell, R.A.; Schubert, S.C.; Schultz, C.; O’Neal, W.K.; Pradervand, S.; et al. Airway Surface Liquid Volume Regulation Determines Different Airway Phenotypes in Liddle Compared with ENaC-overexpressing Mice. J. Biol. Chem. 2010, 285, 26945-26955. [CrossRef]

7. Aschner, Y.; Downey, G.P. Transforming Growth Factor- $\beta$ : Master Regulator of the Respiratory System in Health and Disease. Am. J. Respir. Cell Mol. Biol. 2016, 54, 647-655. [CrossRef]

8. Zhou, R.; Patel, S.V.; Snyder, P.M. Nedd4-2 catalyzes ubiquitination and degradation of cell surface ENaC. J. Biol. Chem. 2007, 282, 20207-20212. [CrossRef] [PubMed]

9. Duerr, J.; Leitz, D.H.W.; Szczygiel, M.; Dvornikov, D.; Fraumann, S.G.; Kreutz, C.; Zadora, P.K.; Seyhan Agircan, A.; Konietzke, P.; Engelmann, T.A.; et al. Conditional deletion of Nedd4-2 in lung epithelial cells causes progressive pulmonary fibrosis in adult mice. Nat. Commun. 2020, 11, 2012. [CrossRef]

10. Boase, N.A.; Rychkov, G.Y.; Townley, S.L.; Dinudom, A.; Candi, E.; Voss, A.K.; Tsoutsman, T.; Semsarian, C.; Melino, G.; Koentgen, F.; et al. Respiratory distress and perinatal lethality in Nedd4-2-deficient mice. Nat. Commun. 2011, 2, 287. [CrossRef]

11. Kimura, T.; Kawabe, H.; Jiang, C.; Zhang, W.; Xiang, Y.-Y.; Lu, C.; Salter, M.W.; Brose, N.; Lu, W.-Y.; Rotin, D. Deletion of the ubiquitin ligase Nedd4L in lung epithelia causes cystic fibrosis-like disease. Proc. Natl. Acad. Sci. USA 2011, 108, 3216-3221. [CrossRef] [PubMed]

12. Duerr, J.; Gruner, M.; Schubert, S.C.; Haberkorn, U.; Bujard, H.; Mall, M.A. Use of a New-Generation Reverse Tetracycline Transactivator System for Quantitative Control of Conditional Gene Expression in the Murine Lung. Am. J. Respir. Cell Mol. Biol. 2011, 44, 244-254. [CrossRef]

13. Deterding, R.R.; DeBoer, E.M.; Cidon, M.J.; Robinson, T.E.; Warburton, D.; Deutsch, G.H.; Young, L.R. Approaching Clinical Trials in Childhood Interstitial Lung Disease and Pediatric Pulmonary Fibrosis. Am. J. Respir. Crit. Care Med. 2019, 200, 1219-1227. [CrossRef] 
14. Trojanek, J.B.; Cobos-Correa, A.; Diemer, S.; Kormann, M.; Schubert, S.C.; Zhou-Suckow, Z.; Agrawal, R.; Duerr, J.; Wagner, C.J.; Schatterny, J.; et al. Airway Mucus Obstruction Triggers Macrophage Activation and Matrix Metalloproteinase 12-Dependent Emphysema. Am. J. Respir. Cell Mol. Biol. 2014, 51, 709-720. [CrossRef]

15. Cobos-Correa, A.; Trojanek, J.B.; Diemer, S.; Mall, M.A.; Schultz, C. Membrane-bound FRET probe visualizes MMP12 activity in pulmonary inflammation. Nat. Chem. Biol. 2009, 5, 628-630. [CrossRef]

16. Fritzsching, B.; Zhou-Suckow, Z.; Trojanek, J.B.; Schubert, S.C.; Schatterny, J.; Hirtz, S.; Agrawal, R.; Muley, T.; Kahn, N.; Sticht, C.; et al. Hypoxic epithelial necrosis triggers neutrophilic inflammation via IL-1 receptor signaling in cystic fibrosis lung disease. Am. J. Respir. Crit. Care Med. 2015, 191, 902-913. [CrossRef]

17. Mall, M.A.; Harkema, J.R.; Trojanek, J.B.; Treis, D.; Livraghi, A.; Schubert, S.; Zhou, Z.; Kreda, S.M.; Tilley, S.L.; Hudson, E.J.; et al. Development of Chronic Bronchitis and Emphysema in b-Epithelial $\mathrm{Na}^{+}$Channel-Overexpressing Mice. Am. J. Respir. Crit. Care Med. 2008, 177, 730-742. [CrossRef]

18. Zhou, Z.; Treis, D.; Schubert, S.C.; Harm, M.; Schatterny, J.; Hirtz, S.; Duerr, J.; Boucher, R.C.; Mall, M.A. Preventive but Not Late Amiloride Therapy Reduces Morbidity and Mortality of Lung Disease in $\beta E N a C$-overexpressing Mice. Am. J. Respir. Crit. Care Med. 2008, 178, 1245-1256. [CrossRef]

19. Johannesson, B.; Hirtz, S.; Schatterny, J.; Schultz, C.; Mall, M.A. CFTR Regulates Early Pathogenesis of Chronic Obstructive Lung

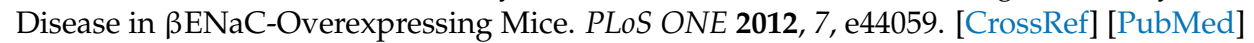

20. Eaton, D.C.; Malik, B.; Bao, H.F.; Yu, L.; Jain, L. Regulation of Epithelial Sodium Channel Trafficking by Ubiquitination. Proc. Am. Thorac. Soc. 2010, 7, 54-64. [CrossRef]

21. Litao, M.K.; Hayes, D., Jr.; Chiwane, S.; Nogee, L.M.; Kurland, G.; Guglani, L. A novel surfactant protein C gene mutation associated with progressive respiratory failure in infancy. Pediatr. Pulmonol. 2016. [CrossRef] [PubMed]

22. Mulugeta, S.; Nguyen, V.; Russo, S.J.; Muniswamy, M.; Beers, M.F. A Surfactant Protein C Precursor Protein BRICHOS Domain Mutation Causes Endoplasmic Reticulum Stress, Proteasome Dysfunction, and Caspase 3 Activation. Am. J. Respir. Cell Mol. Biol. 2005, 32, 521-530. [CrossRef] [PubMed]

23. Kurland, G.; Deterding, R.R.; Hagood, J.S.; Young, L.R.; Brody, A.S.; Castile, R.G.; Dell, S.; Fan, L.L.; Hamvas, A.; Hilman, B.C.; et al. An official American Thoracic Society clinical practice guideline: Classification, evaluation, and management of childhood interstitial lung disease in infancy. Am. J. Respir. Crit. Care Med. 2013, 188, 376-394. [CrossRef] [PubMed]

24. Nureki, S.I.; Tomer, Y.; Venosa, A.; Katzen, J.; Russo, S.J.; Jamil, S.; Barrett, M.; Nguyen, V.; Kopp, M.; Mulugeta, S.; et al. Expression of mutant Sftpc in murine alveolar epithelia drives spontaneous lung fibrosis. J. Clin. Investig. 2018, 128, $4008-4024$. [CrossRef] [PubMed]

25. Venosa, A.; Katzen, J.; Tomer, Y.; Kopp, M.; Jamil, S.; Russo, S.J.; Mulugeta, S.; Beers, M.F. Epithelial Expression of an Interstitial Lung Disease-Associated Mutation in Surfactant Protein-C Modulates Recruitment and Activation of Key Myeloid Cell Populations in Mice. J. Immunol. 2019, 202, 2760-2771. [CrossRef]

26. Hawkins, A.; Guttentag, S.H.; Deterding, R.; Funkhouser, W.K.; Goralski, J.L.; Chatterjee, S.; Mulugeta, S.; Beers, M.F. A nonBRICHOS SFTPC mutant (SP-CI73T) linked to interstitial lung disease promotes a late block in macroautophagy disrupting cellular proteostasis and mitophagy. Am. J. Physiol. Lung Cell Mol. Physiol. 2015, 308, L33-L47. [CrossRef]

27. Deutsch, G.H.; Young, L.R.; Deterding, R.R.; Fan, L.L.; Dell, S.D.; Bean, J.A.; Brody, A.S.; Nogee, L.M.; Trapnell, B.C.; Langston, C.; et al. Diffuse lung disease in young children: Application of a novel classification scheme. Am. J. Respir. Crit. Care Med. 2007, 176, 1120-1128. [CrossRef]

28. Rice, A.; Tran-Dang, M.A.; Bush, A.; Nicholson, A.G. Diffuse lung disease in infancy and childhood: Expanding the chILD classification. Histopathology 2013, 63, 743-755. [CrossRef]

29. Engelmann, T.A.; Knudsen, L.; Leitz, D.H.W.; Duerr, J.; Beers, M.F.; Mall, M.A.; Ochs, M. Linking fibrotic remodeling and ultrastructural alterations of alveolar epithelial cells after deletion of Nedd4-2. Int. J. Mol. Sci. 2021. manuscript submitted.

30. Mall, M.; Bleich, M.; Greger, R.; Schreiber, R.; Kunzelmann, K. The amiloride inhibitable Na+ conductance is reduced by CFTR in normal but not in cystic fibrosis airways. J. Clin. Investig. 1998, 102, 15-21. [CrossRef]

31. Mall, M.; Grubb, B.R.; Harkema, J.R.; O’Neal, W.K.; Boucher, R.C. Increased airway epithelial Na+ absorption produces cystic fibrosis-like lung disease in mice. Nat. Med. 2004, 10, 487-493. [CrossRef]

32. Mall, M.A. Role of cilia, mucus, and airway surface liquid in mucociliary dysfunction: Lessons from mouse models. J. Aerosol. Med. Pulm. Drug Deliv. 2008, 21, 13-24. [CrossRef]

33. Boucher, R.C. Evidence for airway surface dehydration as the initiating event in CF airway disease. J. Intern. Med. 2007, 261, 5-16. [CrossRef]

34. Evans, C.M.; Fingerlin, T.E.; Schwarz, M.I.; Lynch, D.; Kurche, J.; Warg, L.; Yang, I.V.; Schwartz, D.A. Idiopathic Pulmonary Fibrosis: A Genetic Disease That Involves Mucociliary Dysfunction of the Peripheral Airways. Physiol. Rev. 2016, 96, $1567-1591$. [CrossRef] [PubMed]

35. Button, B.; Cai, L.H.; Ehre, C.; Kesimer, M.; Hill, D.B.; Sheehan, J.K.; Boucher, R.C.; Rubinstein, M. A periciliary brush promotes the lung health by separating the mucus layer from airway epithelia. Science 2012, 337, 937-941. [CrossRef]

36. Hancock, L.A.; Hennessy, C.E.; Solomon, G.M.; Dobrinskikh, E.; Estrella, A.; Hara, N.; Hill, D.B.; Kissner, W.J.; Markovetz, M.R.; Grove Villalon, D.E.; et al. Muc5b overexpression causes mucociliary dysfunction and enhances lung fibrosis in mice. Nat. Commun. 2018, 9, 5363. [CrossRef] [PubMed] 
37. Livraghi-Butrico, A.; Wilkinson, K.J.; Volmer, A.S.; Gilmore, R.C.; Rogers, T.D.; Caldwell, R.A.; Burns, K.A.; Esther, C.R., Jr.; Mall, M.A.; Boucher, R.C.; et al. Lung disease phenotypes caused by overexpression of combinations of $\alpha$-, $\beta$-, and $\gamma$-subunits of the epithelial sodium channel in mouse airways. Am. J. Physiol. Lung Cell Mol. Physiol. 2018, 314, L318-L331. [CrossRef]

38. Kaltofen, T.; Haase, M.; Thome, U.H.; Laube, M. Male Sex is Associated with a Reduced Alveolar Epithelial Sodium Transport. PLoS ONE 2015, 10, e0136178. [CrossRef] [PubMed]

39. Jia, J.; Conlon, T.M.; Ballester Lopez, C.; Seimetz, M.; Bednorz, M.; Zhou-Suckow, Z.; Weissmann, N.; Eickelberg, O.; Mall, M.A.; Yildirim, A. Cigarette smoke causes acute airway disease and exacerbates chronic obstructive lung disease in neonatal mice. Am. J. Physiol. Lung Cell Mol. Physiol. 2016, 311, L602-L610. [CrossRef]

40. Balázs, A.; Mall, M.A. Mucus obstruction and inflammation in early cystic fibrosis lung disease: Emerging role of the IL-1 signaling pathway. Pediatric pulmonology 2019, 54 (Suppl. 3), S5-S12. [CrossRef]

41. Montgomery, S.T.; Dittrich, A.S.; Garratt, L.W.; Turkovic, L.; Frey, D.L.; Stick, S.M.; Mall, M.A.; Kicic, A. Interleukin-1 is associated with inflammation and structural lung disease in young children with cystic fibrosis. J. Cyst. Fibros. 2018, 17, 715-722. [CrossRef]

42. Montgomery, S.T.; Mall, M.A.; Kicic, A.; Stick, S.M. Hypoxia and sterile inflammation in cystic fibrosis airways: Mechanisms and potential therapies. Eur. Respir. J. 2017, 49. [CrossRef] [PubMed]

43. Perl, A.-K.T.; Tichelaar, J.W.; Whitsett, J.A. Conditional gene expression in the respiratory epithelium of the mouse. Transgenic Res. 2002, 11, 21-29. [CrossRef] [PubMed]

44. Manning, J.A.; Shah, S.S.; Nikolic, A.; Henshall, T.L.; Khew-Goodall, Y.; Kumar, S. The ubiquitin ligase NEDD4-2/NEDD4L regulates both sodium homeostasis and fibrotic signaling to prevent end-stage renal disease. Cell Death Dis. 2021, $12,398$. [CrossRef] [PubMed]

45. Henshall, T.L.; Manning, J.A.; Alfassy, O.S.; Goel, P.; Boase, N.A.; Kawabe, H.; Kumar, S. Deletion of Nedd4-2 results in progressive kidney disease in mice. Cell Death Differ. 2017, 24, 2150-2160. [CrossRef] [PubMed]

46. Jiang, C.; Kawabe, H.; Rotin, D. The ubiquitin ligase Nedd4L regulates the Na/K/2Cl co-transporter NKCC1/SLC12A2 in the colon. J. Biol. Chem. 2017. [CrossRef] [PubMed]

47. Goel, P.; Manning, J.A.; Kumar, S. NEDD4-2 (NEDD4L): The ubiquitin ligase for multiple membrane proteins. Gene 2015, 557, 1-10. [CrossRef]

48. Kuratomi, G.; Komuro, A.; Goto, K.; Shinozaki, M.; Miyazawa, K.; Miyazono, K.; Imamura, T. NEDD4-2 (neural precursor cell expressed, developmentally down-regulated 4-2) negatively regulates TGF-beta (transforming growth factor-beta) signalling by inducing ubiquitin-mediated degradation of Smad2 and TGF-beta type I receptor. Biochem. J. 2005, 386, 461-470. [CrossRef] [PubMed]

49. Persaud, A.; Alberts, P.; Amsen, E.M.; Xiong, X.; Wasmuth, J.; Saadon, Z.; Fladd, C.; Parkinson, J.; Rotin, D. Comparison of substrate specificity of the ubiquitin ligases Nedd4 and Nedd4-2 using proteome arrays. Mol. Syst. Biol. 2009, 5, 333. [CrossRef] [PubMed]

50. Baron, U.; Freundlieb, S.; Gossen, M.; Bujard, H. Co-regulation of two gene activities by tetracycline via a bidirectional promoter. Nucleic Acids Res. 1995, 23, 3605-3606. [CrossRef] [PubMed]

51. Schoenig, K.; Schwenk, F.; Rajewsky, K.; Hermann, B. Stringent doxycycline dependent control of CRE recombinase in vivo. Nucleic Acids Res. 2002, 30, e134. [CrossRef]

52. Glasser, S.W.; Burhans, M.S.; Korfhagen, T.R.; Na, C.-L.; Sly, P.D.; Ross, G.F.; Ikegami, M.; Whitsett, J.A. Altered stability of pulmonary surfactant in SP-C-deficient mice. Proc. Natl. Acad. Sci. USA 2001, 98, 6366-6371. [CrossRef]

53. Schindelin, J.; Arganda-Carreras, I.; Frise, E.; Kaynig, V.; Longair, M.; Pietzsch, T.; Preibisch, S.; Rueden, C.; Saalfeld, S.; Schmid, B.; et al. Fiji: An open-source platform for biological-image analysis. Nat. Methods 2012, 9, 676-682. [CrossRef]

54. Schindelin, J.; Rueden, C.T.; Hiner, M.C.; Eliceiri, K.W. The ImageJ ecosystem: An open platform for biomedical image analysis Mol. Reprod. Dev. 2015, 82, 518-529. [CrossRef]

55. Evans, C.M.; Williams, O.W.; Tuvim, M.J.; Nigam, R.; Mixides, G.P.; Blackburn, M.R.; DeMayo, F.J.; Burns, A.R.; Smith, C.; Reynolds, S.D.; et al. Mucin is produced by clara cells in the proximal airways of antigen-challenged mice. Am. J. Respir. Cell Mol. Biol. 2004, 31, 382-394. [CrossRef] [PubMed]

56. Beers, M.F.; Kim, C.Y.; Dodia, C.; Fisher, A.B. Localization, synthesis, and processing of surfactant protein SP-C in rat lung analyzed by epitope-specific antipeptide antibodies. J. Biol. Chem. 1994, 269, 20318-20328. [CrossRef]

57. Beers, M.F.; Lomax, C. Synthesis and processing of hydrophobic surfactant protein C by isolated rat type II cells. Am. J. Physiol. 1995, 269, L744-L753. [CrossRef]

58. Beers, M.F.; Bates, S.R.; Fisher, A.B. Differential extraction for the rapid purification of bovine surfactant protein B. Am. J. Physiol. 1992, 262, L773-L778. [CrossRef]

59. Cao, Y.; Tao, J.Q.; Bates, S.R.; Beers, M.F.; Haczku, A. IL-4 induces production of the lung collectin surfactant protein-D. J. Allergy. Clin. Immunol. 2004, 113, 439-444. [CrossRef] [PubMed]

60. Grubb, B.; Paradiso, A.; Boucher, R. Anomalies in ion transport in CF mouse tracheal epithelium. Am. J. Physiol. 1994, 267, C293-C300. [CrossRef]

61. Anagnostopoulou, P.; Dai, L.; Schatterny, J.; Hirtz, S.; Duerr, J.; Mall, M.A. Allergic airway inflammation induces a pro-secretory epithelial ion transport phenotype in mice. Eur. Respir. J. 2010, 36, 1436-1447. [CrossRef] [PubMed] 
62. Pfaffl, M.W. A new mathematical model for relative quantification in real-time RT-PCR. Nucleic Acids Res. 2001, 29, e45. [CrossRef] [PubMed]

63. Nonnenmacher, C.; Dalpke, A.; Rochon, J.; Flores-de-Jacoby, L.; Mutters, R.; Heeg, K. Real-time polymerase chain reaction for detection and quantification of bacteria in periodontal patients. J. Periodontol. 2005, 76, 1542-1549. [CrossRef] [PubMed] 